\title{
Perpendicular Giant Magnetoresistance and Magnetic Properties of Co/Cu Nanowire Arrays Affected by Period Number and Copper Layer Thickness
}

\author{
Juan Han, Xiufang Qin, Zhiyong Quan, Lanfang Wang, and Xiaohong Xu \\ School of Chemistry and Materials Science, Key Laboratory of Magnetic Molecules and Magnetic Information Materials, \\ Ministry of Education, Shanxi Normal University, Linfen 041004, China
}

Correspondence should be addressed to Xiaohong Xu; xuxh@sxnu.edu.cn

Received 20 September 2016; Accepted 15 November 2016

Academic Editor: Mohindar S. Seehra

Copyright (C) 2016 Juan Han et al. This is an open access article distributed under the Creative Commons Attribution License, which permits unrestricted use, distribution, and reproduction in any medium, provided the original work is properly cited.

\begin{abstract}
One-dimensional magnetic nanowires have attracted much attention in the last decades due to their unique physical properties and potential applications in magnetic recording and spintronics. In this work, ordered arrays of $\mathrm{Co} / \mathrm{Cu}$ multilayered nanowires which can be exploited to develop magnetoresistive sensors were successfully prepared using porous anodic alumina (PAA) templates. The structure and morphology of the multilayered nanowire arrays were characterized by transmission electron microscopy and scanning electron microscopy. The nanowire arrays are highly ordered and the average diameter is about $50 \mathrm{~nm}$, which is controlled by the pore diameter of the PAA templates. The influences of period number and $\mathrm{Cu}$ layer thickness on the magnetic and the giant magnetoresistance (GMR) properties were investigated. The coercivity and remanence ratio increase first and then gradually tend to be stable with the increase of period number and the Cu layer thickness, while the GMR ratio increases first and then decreases with the increase of the period number accompanied by an oscillatory behavior of GMR as the Cu layer thickness changes, which are ascribed to the spin dependence electron scattering in the multilayers. The optimum GMR of $-13 \%$ appears at Co (50 $\mathrm{nm}) / \mathrm{Cu}$ $(5 \mathrm{~nm})$ with 200 deposition cycles in our experimental conditions.
\end{abstract}

\section{Introduction}

Giant magnetoresistance (GMR) effect is a phenomenon where the resistivity of the material will be affected significantly with the application of an external magnetic field. Since the discovery of the GMR effect in 1988 [1-3], GMR multilayered structures consisting of ferromagnetic layers separated by a nonmagnetic spacer layer have been focused on due to their unique potential in technological applications, such as high-density data storage, GMR sensors, and magnetic random access memory. Particularly, multilayered nanowires consisting of alternating magnetic and nonmagnetic layers are an ideal system to investigate GMR effect in the current perpendicular to the plane (CPP) geometry as it has been shown to exhibit a more significant GMR effect and high aspect ratio (length/diameter) of the multilayered nanowires leading to larger resistance that enables high accuracy in the measurements [4]. One of the frequently used fabrication methods of the high-aspect-ratio multilayered nanowires is the electrodeposition technique due to its simplicity, convenience, and cost-effectiveness compared to the other preparation techniques that have been employed such as chemical vapor deposition, molecular beam epitaxy, and magnetron sputtering [5-8]. So far, great efforts have been devoted to the research on the CPP-GMR of $\mathrm{CoNi} / \mathrm{Cu}$ [9-11], $\mathrm{NiFe} / \mathrm{Cu}$ [12-14], and $\mathrm{Co} / \mathrm{Cu}[7,15-17]$ multilayered nanowires and it has been shown that the GMR and the magnetic properties of multilayer nanowire arrays are affected by a variety of factors, including the structure of the materials, wire diameter, wire total length, composition, layer thickness, and other factors. However, only few studies have systematically investigated the effects of the period number and copper layer thickness on the magnetic properties and the CPP-GMR [5-7].

In this study, the $\mathrm{Co} / \mathrm{Cu}$ multilayered nanowire arrays are considered to be an attractive system for gaining insights into the CPP-GMR and magnetic properties due to the nanowires' 
perfect band matching and lattice matching $[17,18] . \mathrm{Co} / \mathrm{Cu}$ multilayered nanowire arrays were prepared in PAA templates via single bath by electrochemical method and the effects of repeat period number and copper layer thickness on magnetic properties and CPP-GMR of $\mathrm{Co} / \mathrm{Cu}$ nanowire arrays were studied. It is evident from the experiment that the periodicity of the multilayered nanowires and the nonmagnetic layer thickness play a crucial role in deciding the magnetic and CPP-GMR of the multilayered nanowire arrays.

\section{Experimental Details}

High purity aluminum foil (99.999\%, $0.2 \mathrm{~mm}$ thickness) was first degreased in acetone and ethanol for $10 \mathrm{~min}$ and then annealed at $500^{\circ} \mathrm{C}$ under vacuum for $3 \mathrm{~h}$ to remove the mechanical stress. Afterwards, the aluminum foil was electropolished in a mixture of $\mathrm{HClO}_{4}$ and $\mathrm{C}_{2} \mathrm{H}_{5} \mathrm{OH}(1: 4$ volume ratio) and then rinsed carefully with distilled water. The first anodization was carried out in $0.3 \mathrm{M}$ oxalic acid at $5^{\circ} \mathrm{C}$ for $5 \mathrm{~h}$ under a constant voltage of $40 \mathrm{~V}$. After the anodized layer was dissolved in a mixture of phosphoric acid (6.0 wt $\%)$ and chromic acid $(1.8 \mathrm{wt} \%)$ at $60^{\circ} \mathrm{C}$ for $3 \mathrm{~h}$, the second anodization was done under the same conditions as the first one. A mixed solution of $0.1 \mathrm{M} \mathrm{CuCl}_{2}$ and $20 \% \mathrm{HCl}$ was employed to etch away the aluminum, resulting in freestanding PAA. In addition, a subsequent etching treatment was performed in a $5 \mathrm{wt} \% \mathrm{H}_{3} \mathrm{PO}_{4}$ solution at $30^{\circ} \mathrm{C}$ for $50 \mathrm{~min}$ to remove the barrier layer and slightly widen the pores of the PAA template.

The electrodeposition of the multilayered nanowires was performed at $25^{\circ} \mathrm{C}$ using single bath by electrochemical method. $\mathrm{Ag} / \mathrm{AgCl}$ (in $4 \mathrm{MKCl}$ ) served as the reference electrode and a $\mathrm{Pt}$ wire served as the counter electrode. The electrolytic solution contains $84.3 \mathrm{~g} / \mathrm{L} \mathrm{CoSO}_{4} \cdot 7 \mathrm{H}_{2} \mathrm{O}, 0.57 \mathrm{~g} / \mathrm{L}$ $\mathrm{CuSO}_{4}$, and $50 \mathrm{~g} / \mathrm{L} \mathrm{H}_{3} \mathrm{BO}_{3}$ with the $\mathrm{pH}$ value kept around 3.7. The multilayered nanowires were electrodeposited using an electrochemical workstation technique in a standard threeelectrode mode by periodically switching the deposition potential between $-1.0 \mathrm{~V}$ and $-0.52 \mathrm{~V}$ for the deposition of the $\mathrm{Co}$ and $\mathrm{Cu}$ layers, respectively, and the thickness of each layer was controlled conveniently by the pulse duration because the thickness is proportional to the electrodeposition time under the same experimental condition.

The morphology and structural analysis of nanowires were measured by scanning electron microscopy (SEM) and transmission electron microscopy (TEM). For SEM and TEM observation, the PAA template was dissolved in $1 \mathrm{M} \mathrm{NaOH}$ solution and the residual $\mathrm{NaOH}$ solution absorbed on the surface of the PAA template was removed by rinsing the nanowires carefully with deionized water. The magnetic properties were measured by vibrating sample magnetometer (VSM) and the GMR measurements were performed by physical property measurement system (PPMS, Quantum Design PPMS-9) at room temperature and the GMR percentage was calculated according to the definition:

$$
\mathrm{GMR}=\frac{\left(R_{H}-R_{0}\right)}{R_{0}},
$$

where $R_{H}$ is the resistance in the applied magnetic field $H$ and $R_{0}$ is the resistance of the sample in zero magnetic field. Since the room temperature GMR is more appealing for industrial applications, this current work presents only room temperature GMR.

The model to carry out the GMR measurements is shown in Figure 1. After the electrodeposition of the nanowires, the sample was attached on a glass sheet by silver conductive epoxy and the top side of the unfilled PAA is etched away by $\mathrm{NaOH}$ through controlling appropriate reactive time so that the nanowires can emerge from the template to contact with a tiny drop of silver epoxy for GMR measurement. Using this method, the CPP-GMR of the nanowires at the desired position on the sample can be measured so that it is possible to perform a number of measurements at different positions on the same sample by dropping the silver epoxy at different positions.

\section{Results and Discussion}

Figure 2(a) is the potential-time $(E-t)$ profile during the $\mathrm{Co} / \mathrm{Cu}$ nanowires electrodeposition process. When a low negative potential is applied, only $\mathrm{Cu}$ can be deposited, while at higher negative potential Co can be deposited to form a ferromagnetic layer. The current was recorded in the process as can be seen from Figure 2(b). The current of each cycle is basically the same and no significant increase of the recorded current was observed during the electrodeposition process, indicating that the quantity of the electric charge of each period is equal, which is a prerequisite to ensure the bilayer thickness constancy of each layer. As described above, the thickness of the Co layers and the $\mathrm{Cu}$ layers can be conveniently controlled by changing the time strictly in the deposition process.

The $\mathrm{Co} / \mathrm{Cu}$ nanowires were liberated from the PAA template by dissolving the PAA template in $1 \mathrm{M} \mathrm{NaOH}$ solution and washing it several times with deionized water. Figure 3(a) shows the SEM image of the $\mathrm{Co} / \mathrm{Cu}$ nanowires prepared at $t_{\mathrm{Co}}=21 \mathrm{~s}$ and $t_{\mathrm{Cu}}=17 \mathrm{~s}$ after removing the PAA template. By removing the PAA template, the nanowires are bundled together. The typical TEM images of $\mathrm{Co} / \mathrm{Cu}$ prepared at $t_{\mathrm{Co}}=21 \mathrm{~s}$ and $t_{\mathrm{Cu}}=17 \mathrm{~s}$ are shown in Figure $3(\mathrm{~b})$. It reveals that the nanowires are smooth and uniform along the length. The $\mathrm{Co} / \mathrm{Cu}$ multilayered nanowires show a clear bamboo-like structure. The average thickness of Co layer is around $50 \mathrm{~nm}$ and the $\mathrm{Cu}$ layer is $5 \mathrm{~nm}$, which corresponds to $2.38 \mathrm{~nm} / \mathrm{s}$ for the Co rate of growth and $0.3 \mathrm{~nm} / \mathrm{s}$ for $\mathrm{Cu}$. The XRD pattern corresponding to the multilayered nanowires array is shown in Figure 3(c). The hcp (100), (110), and (200) diffraction peaks of Co are observed at $2 \theta=41.73^{\circ}, 75.93^{\circ}$, and $90.61^{\circ}$, respectively. The diffraction peak at $2 \theta$ value of $43.29^{\circ}$ corresponds to the face centered cubic (fcc) (111) crystalline plane of $\mathrm{Cu}$.

In order to study the effect of $\mathrm{Cu}$ layer thickness on the magnetic and CPP-GMR properties, $\mathrm{Co} / \mathrm{Cu}$ multilayered nanowires with different lengths of $\mathrm{Cu}$ layers were fabricated while the Co length was fixed at $50 \mathrm{~nm}$ in each $\mathrm{Co} / \mathrm{Cu}$ unit. The selected $\mathrm{Cu}$ layer lengths are $3 \mathrm{~nm}, 5 \mathrm{~nm}, 10 \mathrm{~nm}, 18 \mathrm{~nm}$, and $30 \mathrm{~nm}$ and the magnetic hysteresis loops were measured with the applied magnetic field parallel to the nanowires. The 


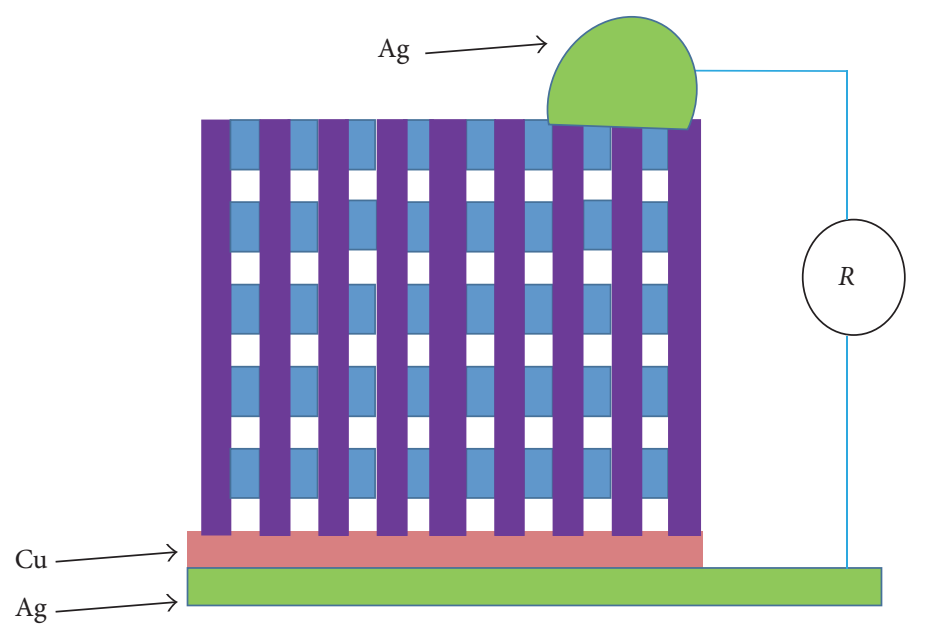

FIGURE 1: Schematic structure of the GMR measurements.

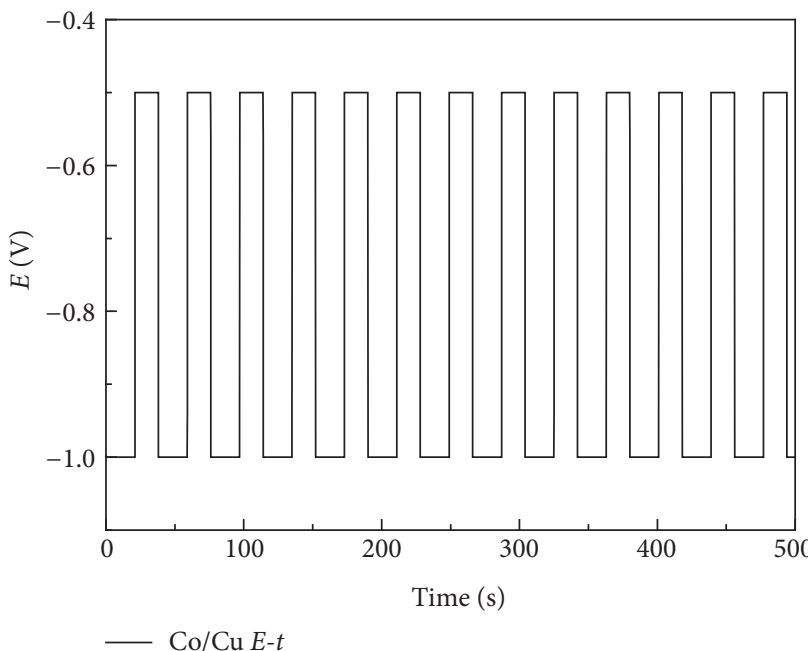

(a)

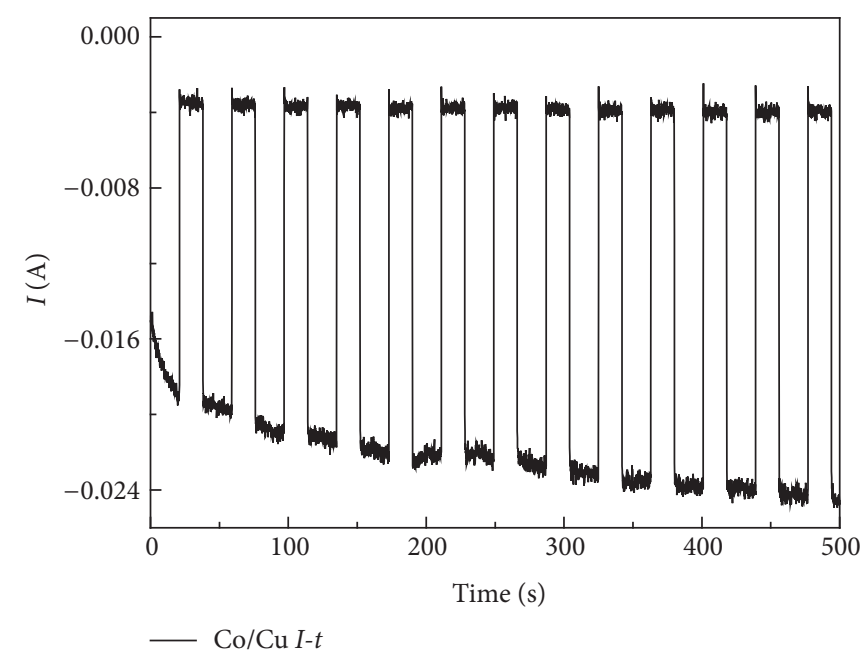

(b)

Figure 2: (a) Typical E- $t$ curve recorded during the Co/Cu nanowires electrodeposition process. (b) The dependence of the observed current and time during the nanowire electrodeposition process.

dependence of magnetic properties on $\mathrm{Cu}$ layer thickness is shown in Figure 4. The coercivity and remanence ratio both increase with the increase of the length of the $\mathrm{Cu}$, which can be caused by a reduced dipole-dipole interaction between the Co layers as the thickness of the $\mathrm{Cu}$ layer increased [9].

Figures 5(a)-5(e) show the GMR curves of the nanowire arrays with different lengths of $\mathrm{Cu}$ under an applied magnetic field parallel to the nanowires. As presented in Figure 5(f), the CPP-GMR shows oscillation dependence on the thickness of the $\mathrm{Cu}$ layer. The GMR oscillates according to the $\mathrm{Cu}$ layer thickness, which is consistent with similar systems in different metallic superlattice structures with a spacer layer [13]. The thickness of the nonmagnetic $\mathrm{Cu}$ layer influences the interlayer exchange coupling between the ferromagnetic layers which will cause incoherent magnetic reversal rotation, thus leading to oscillations in GMR [19]. With the increasing of the $\mathrm{Cu}$ layer, the pinhole density reduces and the layer thickness uniformity improves, which both lead to weakening of the FM coupling. The reduction in FM coupling enables a more random magnetization orientation of the adjacent layers and thus the GMR effect increases. However, with the $\mathrm{Cu}$ layer thickness increasing, there appear inevitable disadvantages in the $\mathrm{Cu}$ layer. The thicker the $\mathrm{Cu}$ layer, the more the defects, and significant spin flipping of the conduction electrons takes place during the transmission process, which will reduce the spin dependent electron scattering, so the GMR declines partly [20]. So, under the common action of the dual mechanisms, the GMR effect presents an oscillation phenomenon with the increase of the thickness of the $\mathrm{Cu}$ layer.

The dependence of magnetic properties on the number of bilayers is displayed in Figure 6 and the coercivity and remanence ratio increase first and then gradually tend to be stable. The possible reason for this phenomenon is that 


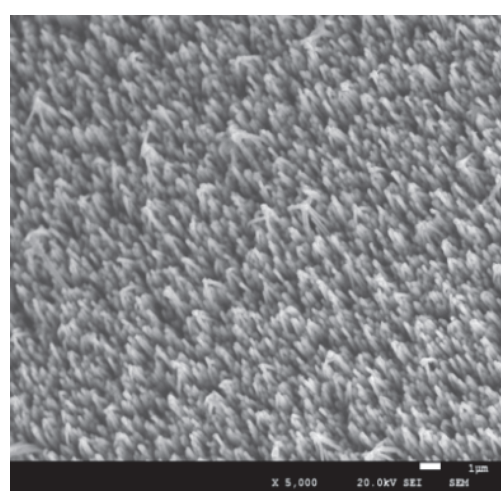

(a)

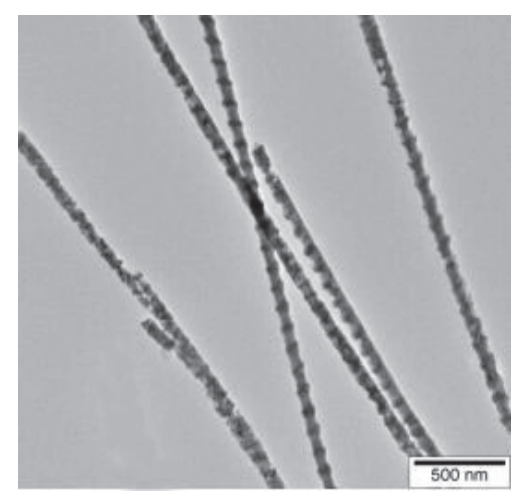

(b)

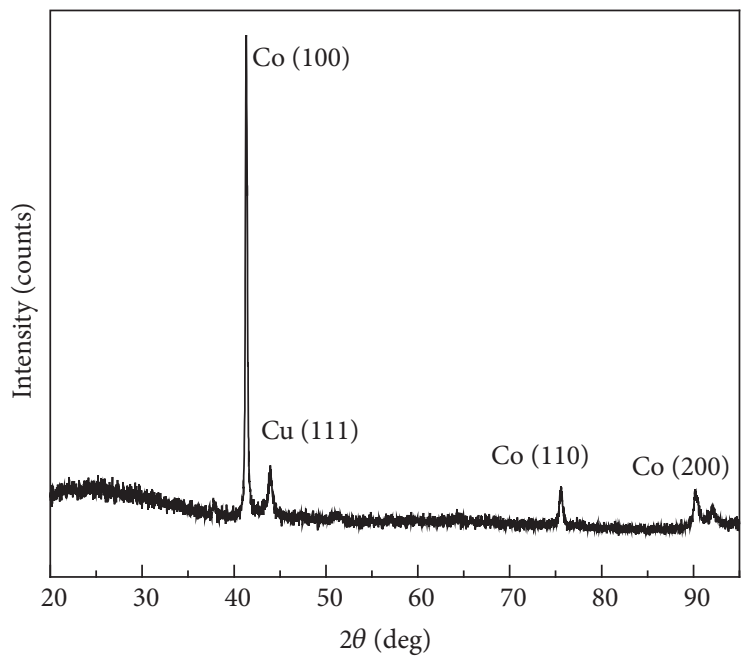

(c)

FIGURE 3: SEM (a), TEM profile image (b), and XRD pattern (c) of the Co $(50 \mathrm{~nm}) / \mathrm{Cu}(5 \mathrm{~nm})$ nanowires prepared at $t_{\mathrm{Co}}=21 \mathrm{~s}$ and $t_{\mathrm{Cu}}=17 \mathrm{~s}$ after removing the PAA template.

coercivity is mainly caused by domain wall pinning effect [21]; with the increase of the length, the domain walls will produce pinning effect and there will be many defects and impurities resulting in more pinning points which increase the coercivity.

The number of bilayers is an important factor that affects CPP-GMR since it directly relates to the material resistance. Here, the variation of bilayers and its effect on the CPP-GMR properties were studied. Based on the previous measure methods, we measured the CPP-GMR hysteresis of $\mathrm{Co} / \mathrm{Cu}$ multilayered nanowires with the applied magnetic field parallel to the nanowires. The period number was varied between 50,100, 150, 200, and 250. Figures 7(a)-7(e) show the CPP-GMR curves of $\mathrm{Co} / \mathrm{Cu}$ multilayered nanowires with different $\mathrm{Co} / \mathrm{Cu}$ bilayers $(50,100,150,200$, and $250 \mathrm{Co} / \mathrm{Cu}$ bilayers) electrodeposited into porous anodic alumina. The 200-bilayer nanowire sample shows - $13 \%$ GMR, while the 50bilayer nanowire sample shows only 0.6\% GMR. Figure 7(f) shows the relationship between CPP-GMR ratio and the number of bilayers of $\mathrm{Co} / \mathrm{Cu}$ multilayered nanowires. We can see that the CPP-GMR ratio increases first and then decreases with the increase of the repeat period number.
The increase can be explained by the fact that an increase in number of bilayers increases the number of interfaces, leading to more interface electron scattering and decreasing the shunting effect of the metallic conductive layer [10], and thus CPP-GMR increases. The decrease is ascribed to the gradual deterioration of the structure as the deposit grows; the multilayer interfaces are more significant at the beginning of the deposit than later. In other words, the gradual inhomogeneities during the deposition process of the bilayers could be responsible for the later reduction in CPPGMR. This result confirms the fact that the interfaces play an important role in CPP-GMR.

\section{Conclusions}

In summary, highly ordered and homogeneously aligned $\mathrm{Co} / \mathrm{Cu}$ multilayered nanowire arrays were prepared by singlebath electrodeposition method. The effects of repeat period number and copper layer thickness on magnetic and CPP$\mathrm{GMR}$ of $\mathrm{Co} / \mathrm{Cu}$ nanowire arrays were investigated. We have highlighted the importance of nonmagnetic layer thickness and the number of bilayers upon the magnetic and CPP-GMR 

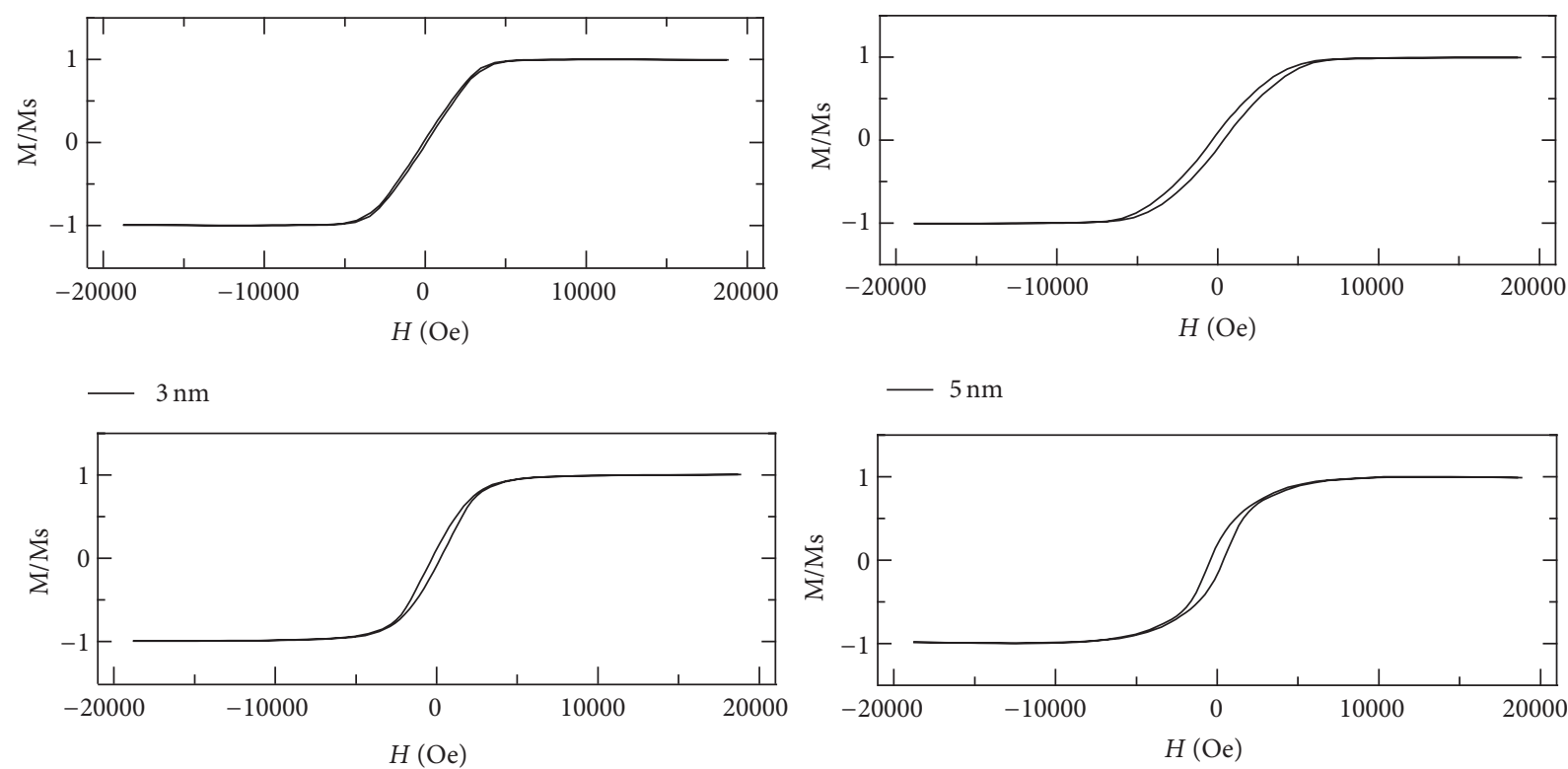

$-10 \mathrm{~nm}$

$-18 \mathrm{~nm}$

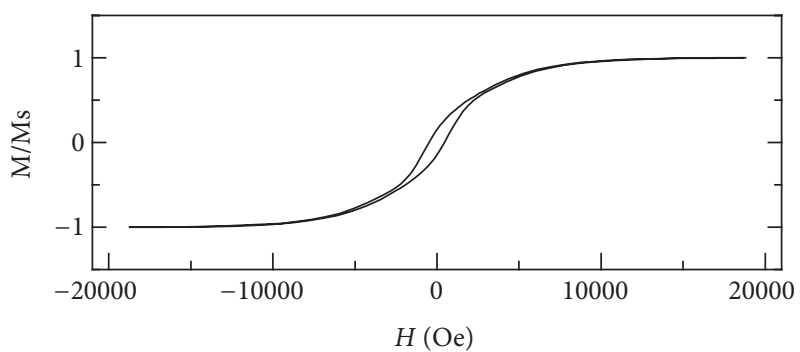

$-30 \mathrm{~nm}$

(a)
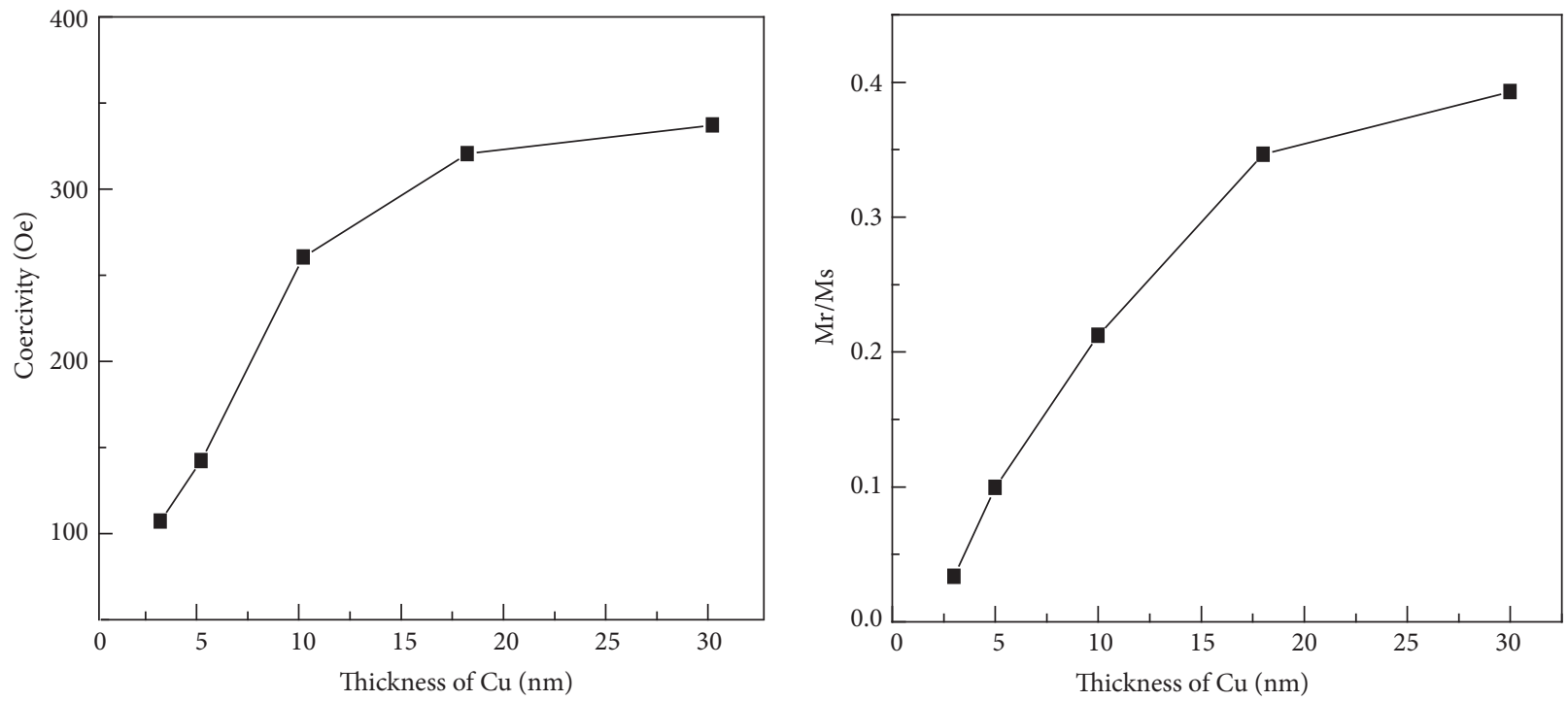

(b)

Figure 4: (a) Magnetic hysteresis loops of the $\mathrm{Co} / \mathrm{Cu}$ nanowires with $\mathrm{Co}(50 \mathrm{~nm})$ and $\mathrm{Cu}$ varied from $3 \mathrm{~nm}$ to $30 \mathrm{~nm}$. (b) Evolution of the coercivity $\left(H_{c}\right)$ and remanence ratio $(\mathrm{Mr} / \mathrm{Ms})$ with the change of $\mathrm{Cu}$ layer thickness under applied magnetic field parallel to the nanowires. 


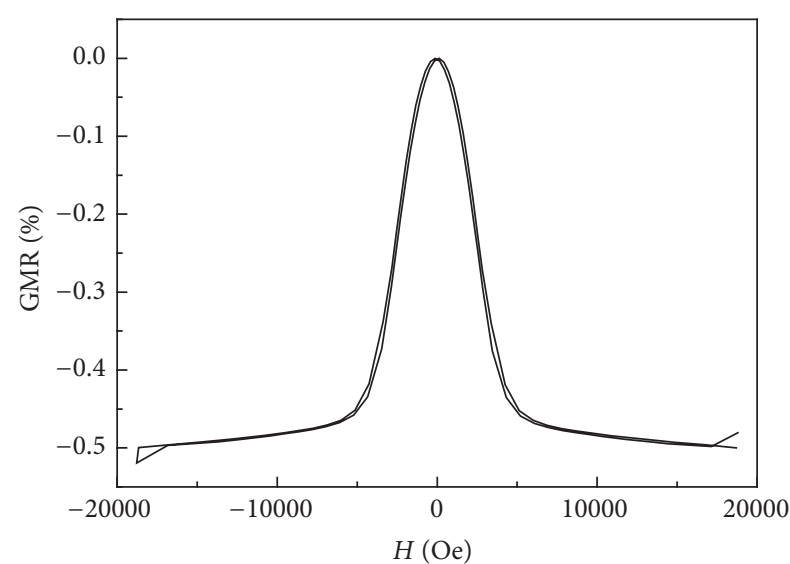

$\mathrm{Cu} 3 \mathrm{~nm}$

(a)

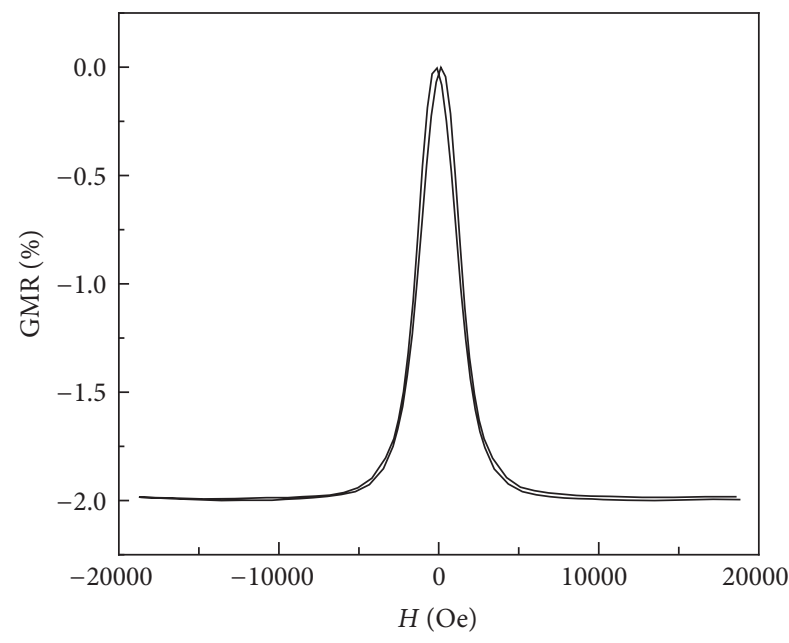

$-\mathrm{Cu} 10 \mathrm{~nm}$

(c)

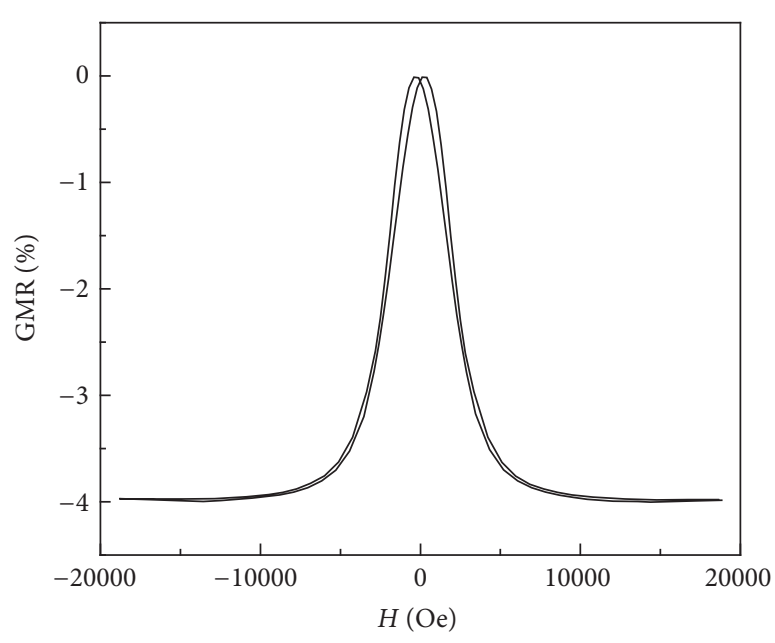

$\mathrm{Cu} 30 \mathrm{~nm}$

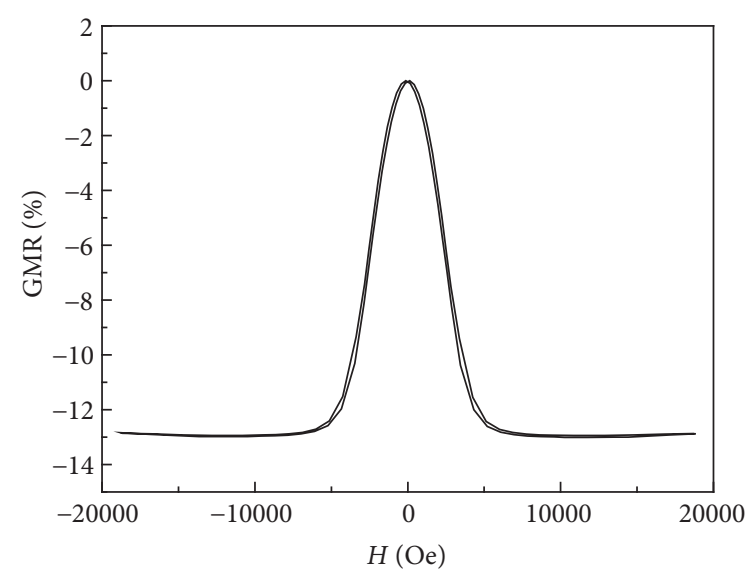

$-\mathrm{Cu} 5 \mathrm{~nm}$

(b)

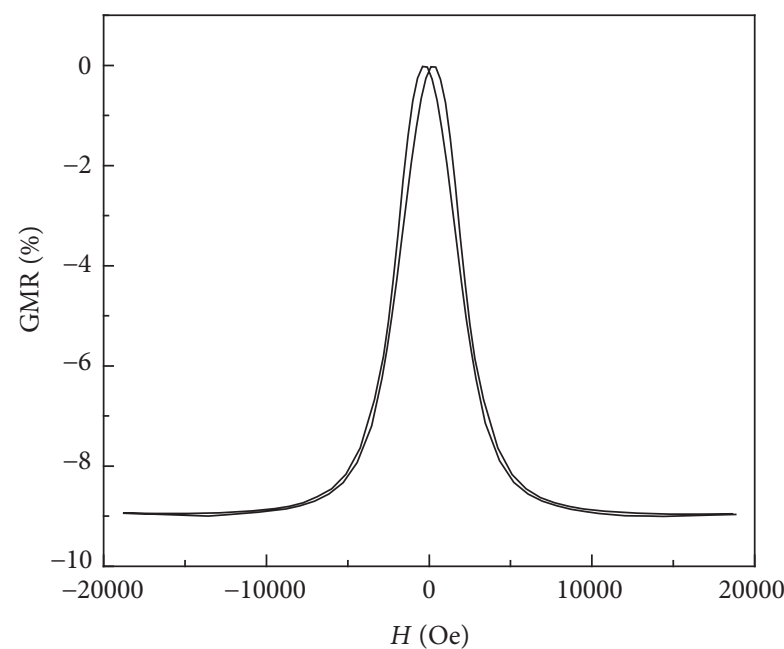

- $\mathrm{Cu} 18 \mathrm{~nm}$

(d)

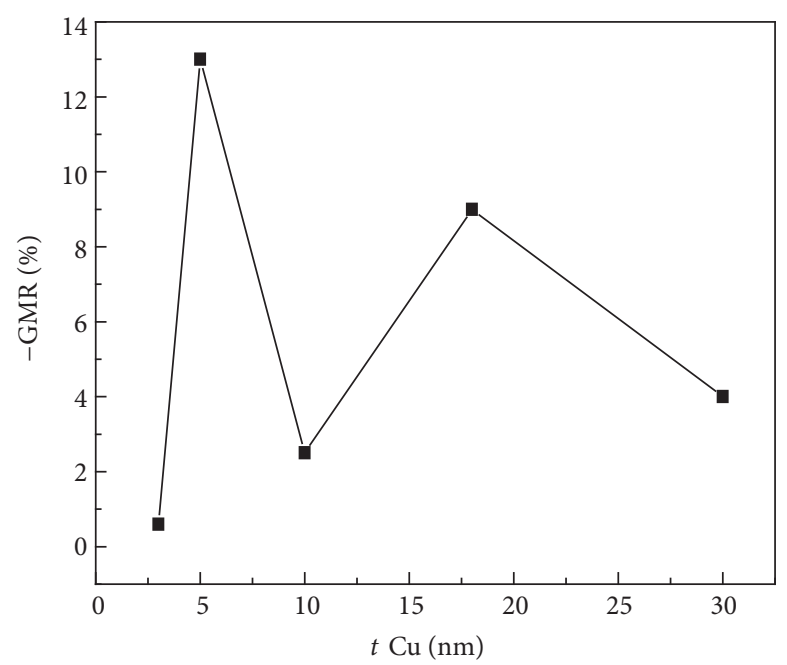

(f)

Figure 5: (a)-(e) The CPP-GMR curves of Co $(50 \mathrm{~nm}) / \mathrm{Cu}(3 \mathrm{~nm}), \mathrm{Co}(50 \mathrm{~nm}) / \mathrm{Cu}(5 \mathrm{~nm}), \mathrm{Co}(50 \mathrm{~nm}) / \mathrm{Cu}(10 \mathrm{~nm}), \mathrm{Co}(50 \mathrm{~nm}) / \mathrm{Cu}(18 \mathrm{~nm})$, and $\mathrm{Co}(50 \mathrm{~nm}) / \mathrm{Cu}(30 \mathrm{~nm})$ multilayered nanowire arrays under applied magnetic field parallel to the nanowires. (f) The relationship between the CPP-GMR ratio and different thicknesses of the $\mathrm{Cu}$ layer of the $\mathrm{Co} / \mathrm{Cu}$ multilayered nanowire arrays under magnetic field parallel to the nanowires. 

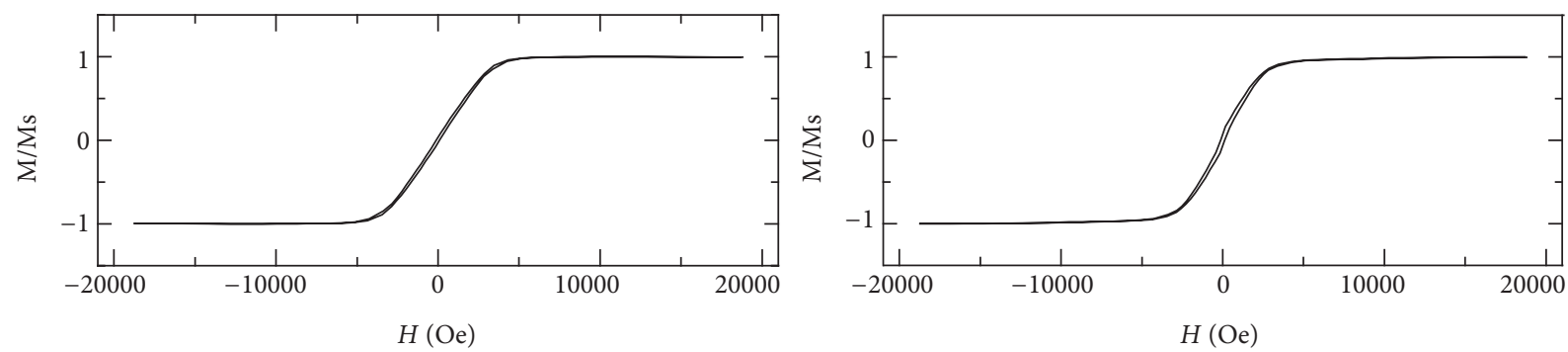

- 50 bilayers

100 bilayers
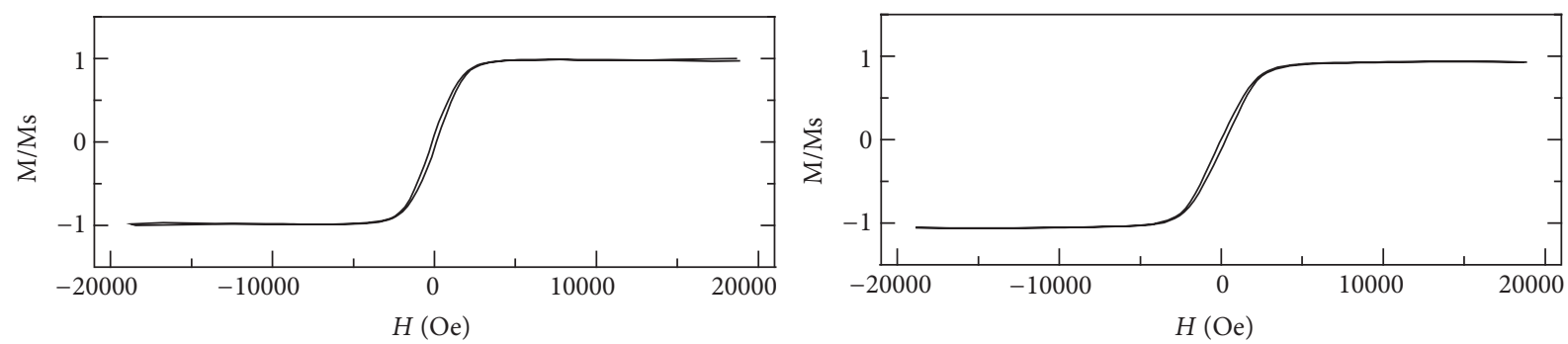

150 bilayers

- 200 bilayers

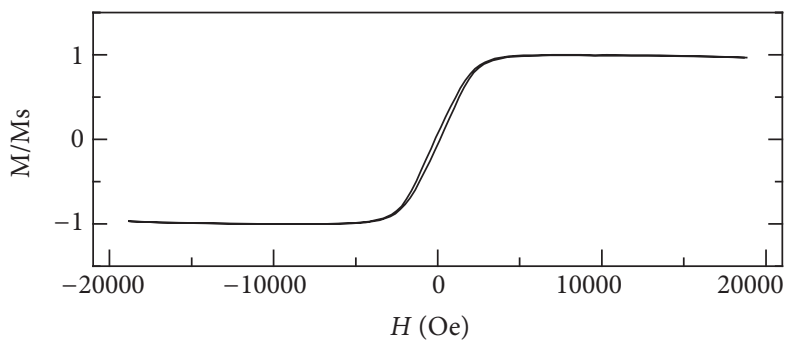

— 250 bilayers

(a)
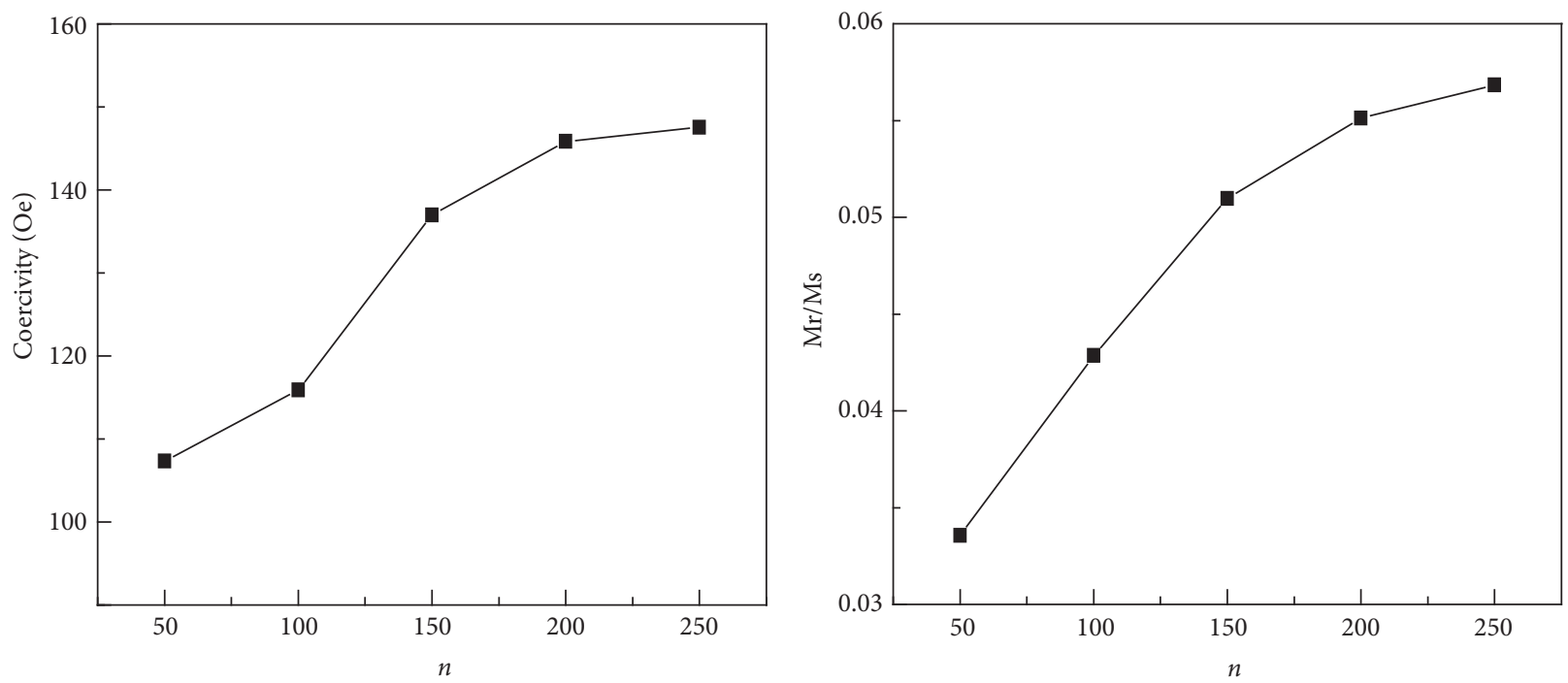

(b)

Figure 6: Magnetic hysteresis loops of $\mathrm{Co} / \mathrm{Cu}$ nanowires with $\mathrm{Co}(50 \mathrm{~nm}) / \mathrm{Cu}(5 \mathrm{~nm})$ of different period numbers and the evolution of the coercivity $\left(H_{\mathrm{c}}\right)$ and remanence ratio $(\mathrm{Mr} / \mathrm{Ms})$ with the change of period number under the applied magnetic field parallel to the nanowires. 


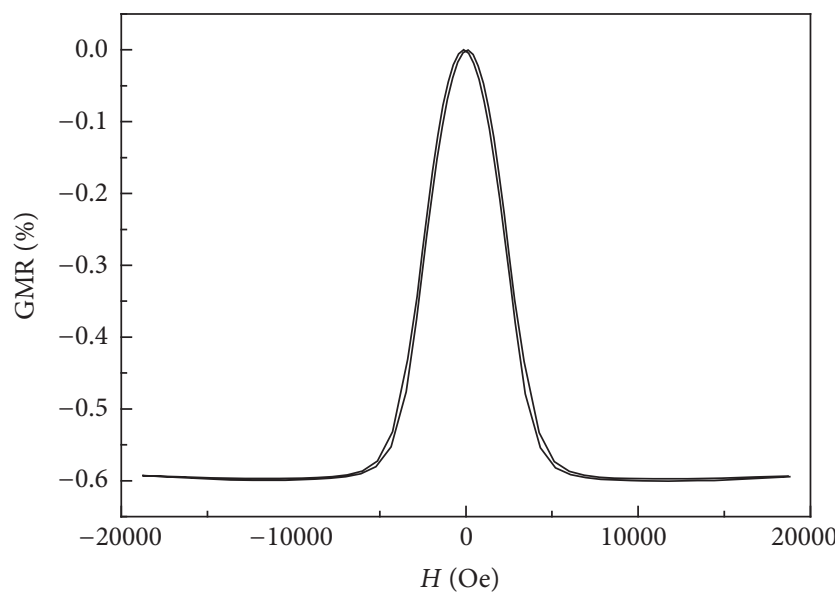

— 50 bilayers

(a)

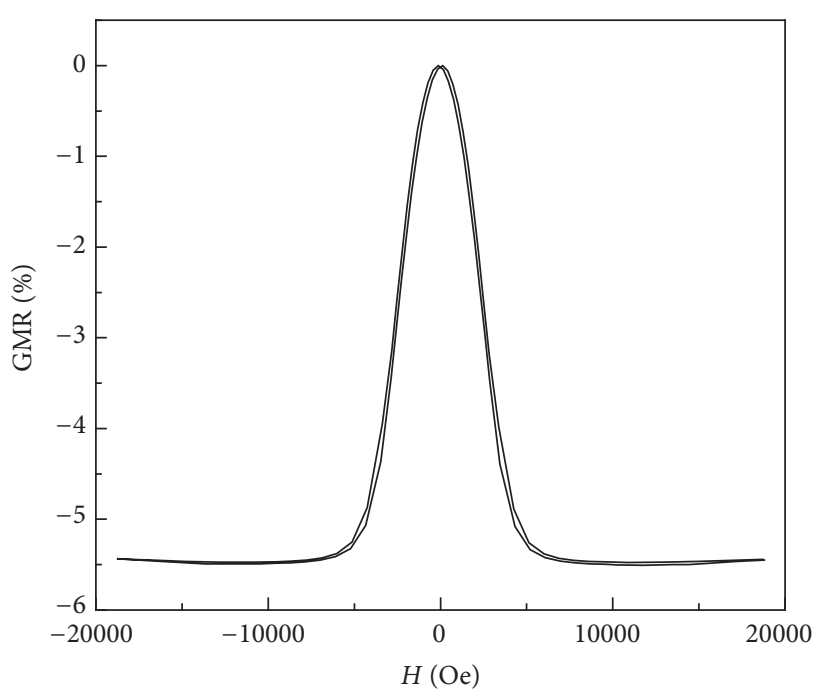

— 150 bilayers

(c)

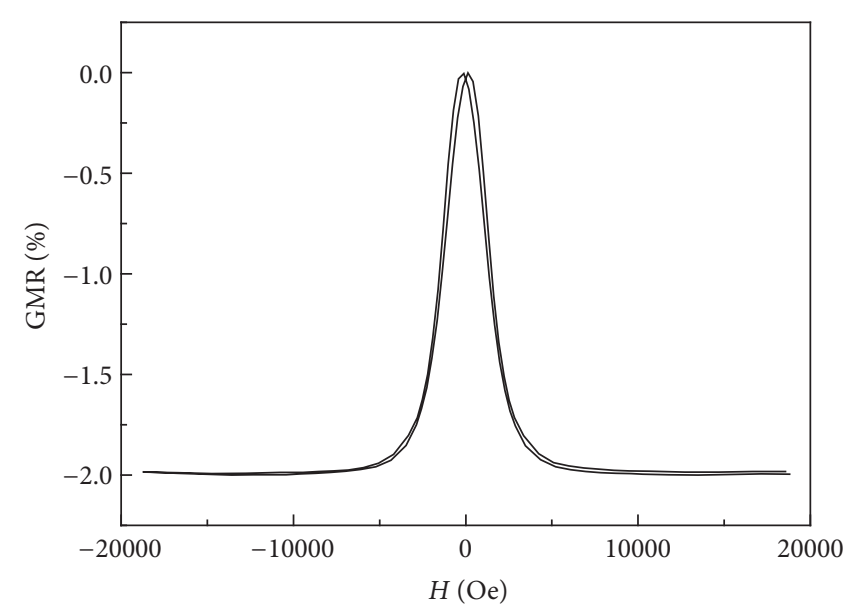

— 250 bilayers

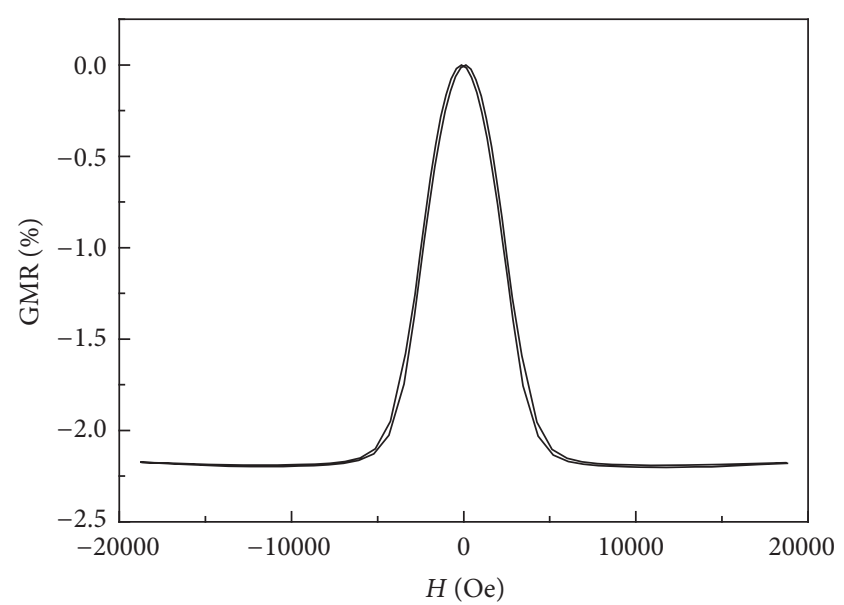

100 bilayers

(b)

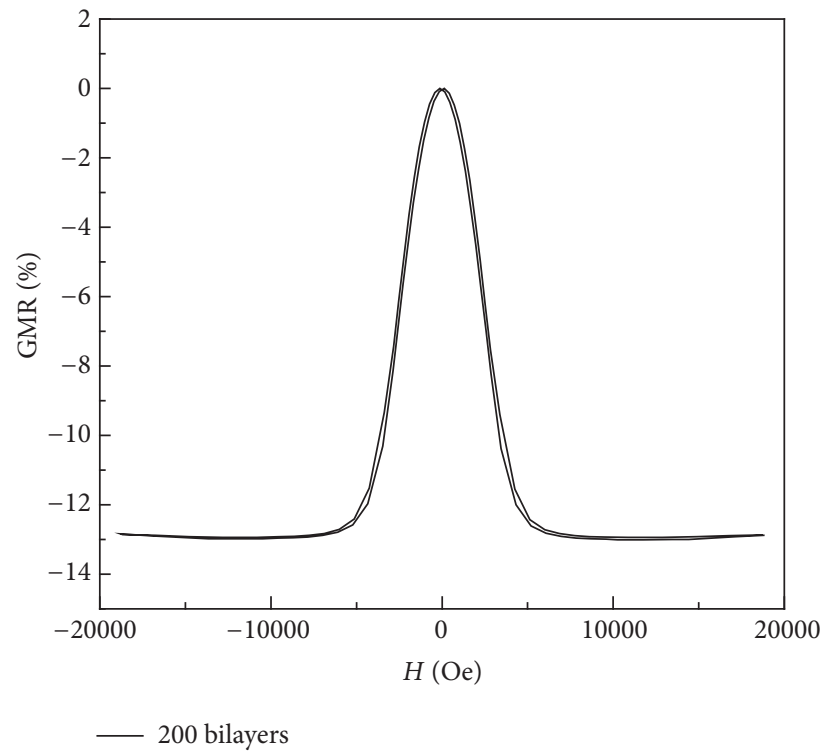

(d)

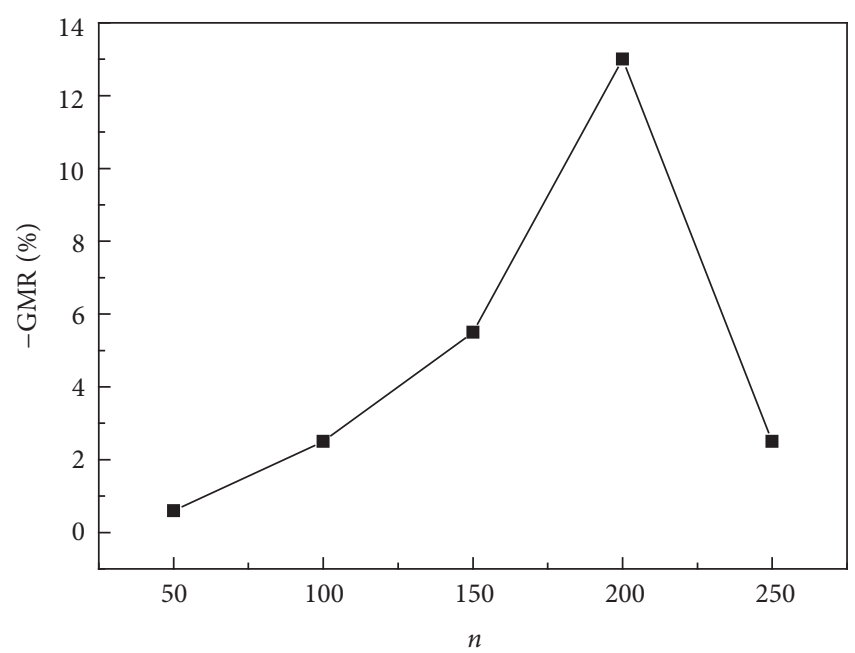

(f)

Figure 7: (a)-(e) The CPP-GMR curves of Co $(50 \mathrm{~nm}) / \mathrm{Cu}(5 \mathrm{~nm})$ with the repeat period number varied from 50 to 250 . (f) The relationship between the CPP-GMR ratio and the number of bilayers of the $\mathrm{Co} / \mathrm{Cu}$ multilayered nanowires electrodeposited into PAA templates. 
properties of multilayered nanowire arrays. The coercivity and remanence ratio increase first and then gradually tend to be stable with the increase of the length of the $\mathrm{Cu}$ and the period number. The result of CPP-GMR indicates an oscillatory behavior with the varying thickness of $\mathrm{Cu}$ layer. The best multilayered nanowire array structure was obtained in Co $(50 \mathrm{~nm}) / \mathrm{Cu}(5 \mathrm{~nm})(n=200)$ and the maximum CPPGMR value can reach $-13 \%$ at room temperature. This study is of vital importance to the potential applications in the fields of nanodevices and is helpful to provide more in-depth understanding of the magnetic properties of the multilayered nanowire arrays.

\section{Competing Interests}

The authors declare that there are no competing interests regarding the publication of this paper.

\section{Acknowledgments}

The work is financially supported by the National High Technology Research and Development Program of China (863 Program, no. 2014AA032904), NSFC (nos. 51571136, 61434002), and Shanxi Scholarship Council of China (2015069).

\section{References}

[1] M. N. Baibich, J. M. Broto, A. Fert et al., "Giant magnetoresistance of (001)Fe/(001)Cr magnetic superlattices," Physical Review Letters, vol. 61, no. 21, pp. 2472-2475, 1988.

[2] G. Binasch, P. Grünberg, F. Saurenbach, and W. Zinn, "Enhanced magnetoresistance in layered magnetic structures with antiferromagnetic interlayer exchange," Physical Review B, vol. 39, no. 7, pp. 4828-4830, 1989.

[3] A. Fert and L. Piraux, "Magnetic nanowires," Journal of Magnetism and Magnetic Materials, vol. 200, no. 1, pp. 338-358, 1999.

[4] I. Bakonyi and L. Péter, "Electrodeposited multilayer films with giant magnetoresistance (GMR): progress and problems," Progress in Materials Science, vol. 55, no. 3, pp. 107-245, 2010.

[5] D. K. Pandya, P. Gupta, S. C. Kashyap, and S. Chaudhary, "Electrodeposition and characterization of $\mathrm{Cu} / \mathrm{Co}$ multilayers: effect of individual $\mathrm{Co}$ and $\mathrm{Cu}$ layers on GMR magnitude and behavior," Journal of Magnetism \& Magnetic Materials, vol. 321, no. 8, pp. 974-978, 2009.

[6] L. Piraux, J. M. George, J. F. Despres et al., "Giant magnetoresistance in magnetic multilayered nanowires," Applied Physics Letters, vol. 65, no. 19, pp. 2484-2486, 1994.

[7] K. Liu, K. Nagodawithana, P. C. Searson, and C. L. Chien, "Perpendicular giant magnetoresistance of multilayered $\mathrm{Co} / \mathrm{Cu}$ nanowires," Physical Review B, vol. 51, no. 11, pp. 7381-7384, 1995.

[8] K. Yakushiji, K. Saito, S. Mitani, K. Takanashi, Y. K. Takahashi, and K. Hono, "Current-perpendicular-to-plane magnetoresistance in epitaxial $\mathrm{Co}_{2} \mathrm{MnSi} / \mathrm{Cr} / \mathrm{Co}_{2} \mathrm{MnSi}$ trilayers," Applied Physics Letters, vol. 88, no. 22, Article ID 222504, pp. 222-504, 2006.

[9] X.-T. Tang, G.-C. Wang, and M. Shima, "Layer thickness dependence of CPP giant magnetoresistance in individual
CoNi/Cu multilayer nanowires grown by electrodeposition," Physical Review B, vol. 75, no. 13, Article ID 134404, 2007.

[10] S. M. S. I. Dulal and E. A. Charles, "Effect of interface number on giant magnetoresistance," Journal of Physics and Chemistry of Solids, vol. 71, no. 3, pp. 309-313, 2010.

[11] T. Ono, Y. Sugita, K. Shigeto, K. Mibu, N. Hosoito, and T. Shinjo, "Magnetoresistance study of $\mathrm{Co} / \mathrm{Cu} / \mathrm{NiFe} / \mathrm{Cu}$ multilayers prepared on V-groove substrates," Physical Review B, vol. 55, no. 21, pp. 14457-14466, 1997.

[12] D. Serrate, J. M. De Teresa, P. A. Algarabel, M. R. Ibarra, and J. Galibert, "Intergrain magnetoresistance up to $50 \mathrm{~T}$ in the half-metallic $\left(\mathrm{Ba}_{0.8} \mathrm{Sr}_{0.2}\right)_{2} \mathrm{FeMoO}_{6}$ double perovskite: spin-glass behavior of the grain boundary," Physical Review B, vol. 71, no. 10, Article ID 104409, 2005.

[13] A. Paul, T. Damm, D. E. Bürgler, S. Stein, H. Kohlstedt, and P. Grünberg, "Optimizing the giant magnetoresistance of $\mathrm{NiFe} / \mathrm{Cu} / \mathrm{Co}$ pseudo spin-valves prepared by magnetron sputtering," Applied Physics Letters, vol. 82, no. 12, pp. 1905-1907, 2003.

[14] D. Lottis, A. Fert, R. Morel et al., "Magnetoresistance in rfsputtered $(\mathrm{NiFe} / \mathrm{Cu} / \mathrm{Co} / \mathrm{Cu})$ spin-valve multilayers," Journal of Applied Physics, vol. 73, no. 10, pp. 5515-5517, 1993.

[15] X. Huang, L. Tan, H. Cho, and B. J. H. Stadler, "Magnetoresistance and spin transfer torque in electrodeposited $\mathrm{Co} / \mathrm{Cu}$ multilayered nanowire arrays with small diameters," Journal of Applied Physics, vol. 105, no. 7, Article ID 07D128, 2009.

[16] S. Hernández, L. Tan, B. J. H. Stadler, and R. H. Victora, "Micromagnetic calculation of spin transfer torque in $\mathrm{Co} / \mathrm{Cu}$ multilayer nanowires," Journal of Applied Physics, vol. 109, no. 7, Article ID 07C916, 2011.

[17] L. Tan and B. J. H. Stadler, "Fabrication and magnetic behavior of $\mathrm{Co} / \mathrm{Cu}$ multilayered nanowires," Journal of Materials Research, vol. 21, no. 11, pp. 2870-2875, 2006.

[18] S. Hernndez, L. Tan, B. J. H. Stadler, and R. H. Victora, "Micromagnetic calculation of spin transfer torque in $\mathrm{Co} / \mathrm{Cu}$ multilayer nanowires," Journal of Applied Physics, vol. 109, no. 7, Article ID 07C916, 2011.

[19] S. S. P. Parkin, N. More, and K. P. Roche, "Oscillations in exchange coupling and magnetoresistance in metallic superlattice structures: $\mathrm{Co} / \mathrm{Ru}, \mathrm{Co} / \mathrm{Cr}$, and $\mathrm{Fe} / \mathrm{Cr}$," Physical Review Letters, vol. 64, no. 19, pp. 2304-2307, 1990.

[20] Y. Xu, D. Ephron, and M. R. Beasley, "Directed inelastic hopping of electrons through metal-insulator-metal tunnel junctions," Physical Review B, vol. 52, no. 4, pp. 2843-2859, 1995.

[21] S.-S. Yan, J. Du, J. L. Weston, G. Zangari, and J. A. Barnard, "Modulated magnetic properties of hard/soft exchange-coupled SmFe/NiFe multilayers," Journal of Magnetism and Magnetic Materials, vol. 231, no. 2-3, pp. 241-245, 2001. 

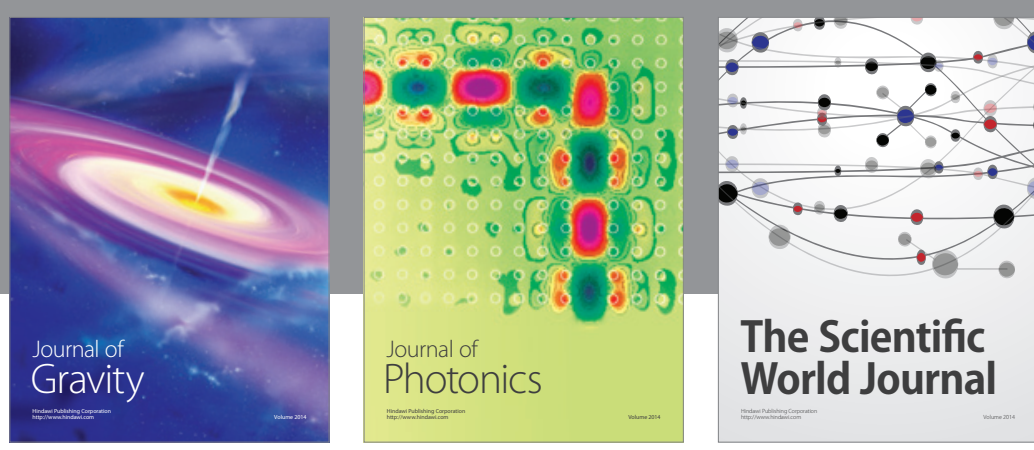

The Scientific World Journal
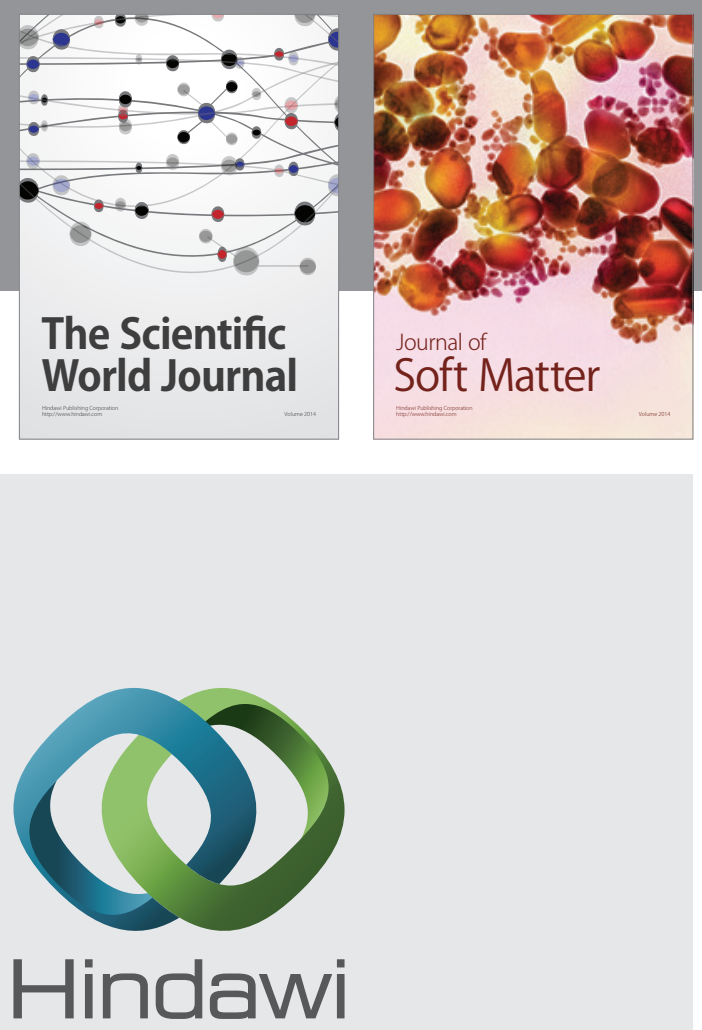

Submit your manuscripts at

http://www.hindawi.com

nternational Journal of

Statistical Mechanics
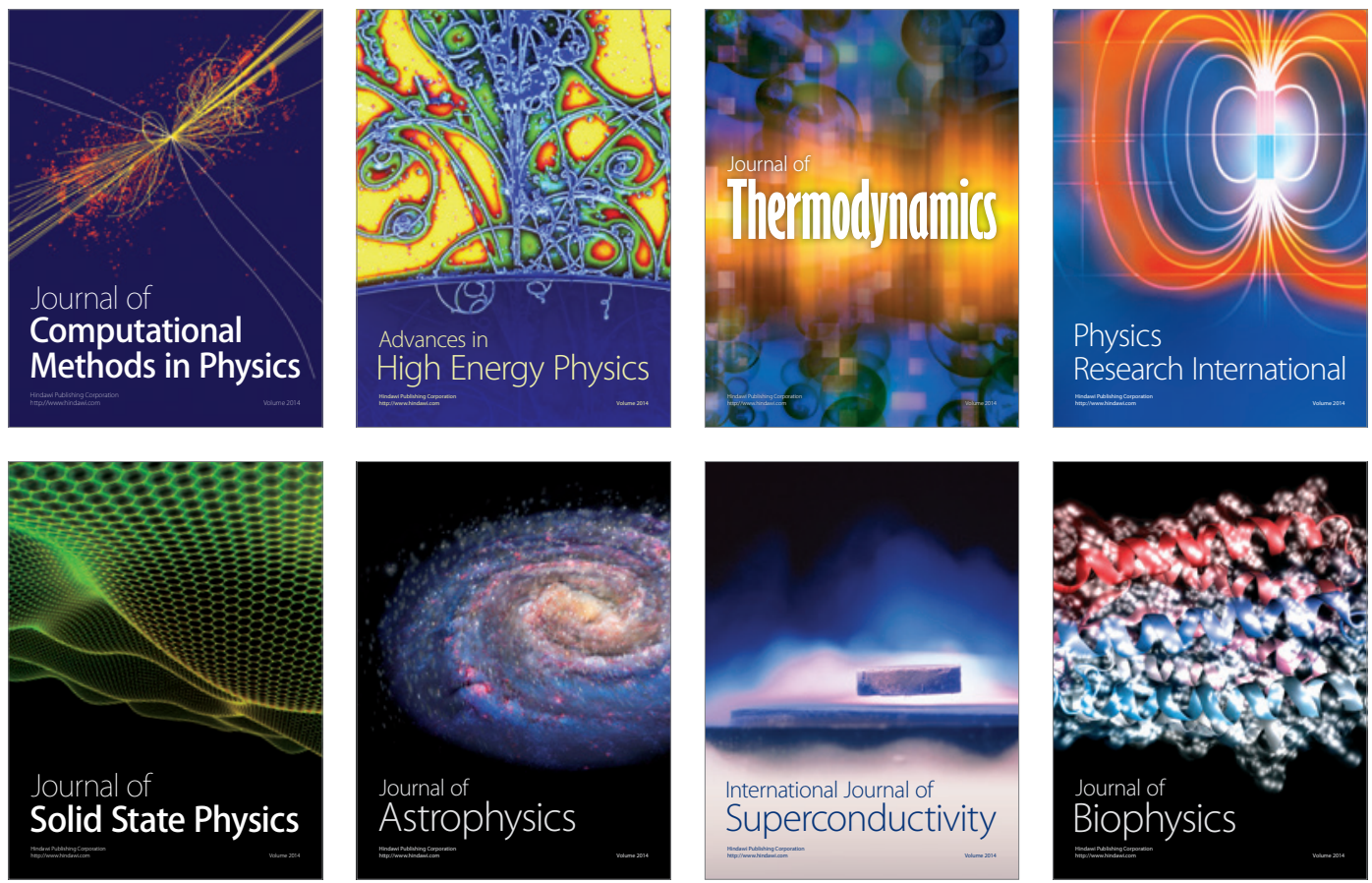
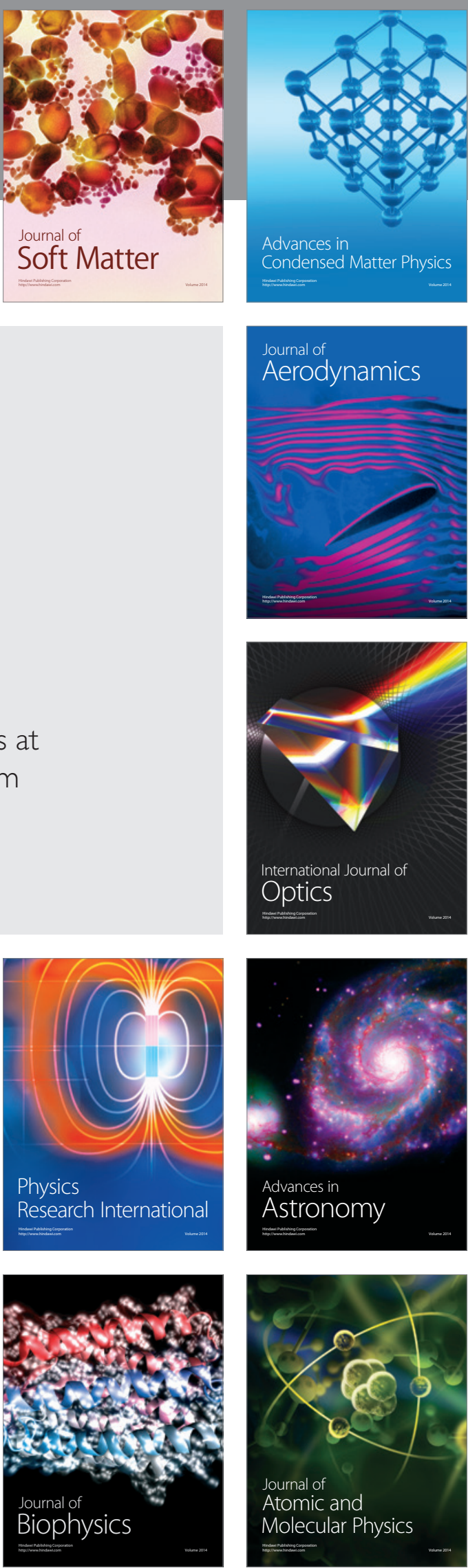